\title{
Simplifying the Determination of Aggregate Stability Indicators of Mollisols
}

\author{
Gisela Vanesa García $\mathbb{B}^{\mathrm{a}, \mathrm{b}}$, Santiago Néstor Tourn ${ }^{\mathrm{b}}$, María Florencia Roldánc, \\ Mariana Mandiola ${ }^{\mathrm{b}}$, and Guillermo Alberto Studdert (10 ${ }^{\mathrm{b}}$ \\ aComisión de Investigaciones Científicas de la Provincia de Buenos Aires, La Plata, Buenos Aires, Argentin; bFacultad \\ de Ciencias Agrarias, Universidad Nacional de Mar del Plata, Unidad Integrada Balcarce, Balcarce, Buenos Aires, \\ Argentina; 'Estación Experimental Sáenz Peña, Instituto Nacional de Tecnología Agropecuaria, Presidencia Roque \\ Sáenz Peña, Chaco, Argentina
}

\begin{abstract}
Aggregate stability (AS) is a very sensitive soil physical health indicator. The complexity of its determination discourages frequent monitoring. We hypothesized that a reduction of steps to determine AS would yield good AS indicators. We evaluated 196 samples from a range of Mollisols from sandy- to clay-loam surface texture from the southeastern Buenos Aires province, Argentina. Six AS indicators were evaluated: aggregate mean weight diameter (MWD) after capillary wetting (CW) $\left(M D_{C W}\right)$, MWD after sudden immersion in water (VW) (MWD $D_{\mathrm{vw}}$ ), change of MWD ( $\triangle M W D$ ), remnant mass of macroaggregates (MAm) after CW (MAm $\left.{ }_{\mathrm{CW}}\right)$, MAm after VW $\left(M A m_{V w}\right)$, and change of MAm between VW and CW $\left(\triangle M A m_{V W-C W}\right)$. Determining $\triangle M W D$ requires six sievings, MWD requires three, $\triangle M A m_{\mathrm{VW}} \mathrm{CW}$ requires two, and MAm requires only one. Indicators after $\mathrm{CW}$ $\left(M W D_{C W}\right.$ and $\left.M A m_{C W}\right)$ were not good AS indicators. Likewise, those determined as a difference between $C W$ and $V W\left(\triangle M W D\right.$ and $\triangle M A m_{V W}-C W$ ) failed to distinguish contrasting AS situations making them unfeasible as universal AS indicators. However, MAm $\mathrm{vw}_{\mathrm{w}}$ explained $99 \%$ of $M \mathrm{MWD}_{\mathrm{vw}}$ variability and adequately distinguished among AS situations. With only one sieving, a good indicator of AS could be obtained, and this would encourage the adoption by soil testing laboratories and frequent soil physical health monitoring by farmers.
\end{abstract}

\section{ARTICLE HISTORY}

Received 22 August 2019

Accepted 7 January 2020

\section{KEYWORDS}

Macroaggregate mass; change of macroaggregate mass; mean weight diameter; change of mean weight diameter

\section{Introduction}

Aggregate stability (AS) has been postulated as the best soil physical health indicator (Aparicio and Costa 2007; Rabot et al. 2018). This is because AS affects soil pore system behavior, soil air and water dynamics, erosion resistance, nutrient cycling, $\mathrm{C}$ sequestration, $\mathrm{CO}_{2}$ emissions, root growth, and crop yields (Bronick and Lal 2005; Rabot et al. 2018). Hence, AS is essential for several soil properties such as bulk density, water infiltration, and soil organic C content (Rabot et al. 2018). Likewise, AS is highly sensitive to soil use and management (Aparicio and Costa 2007; Mandiola et al. 2011; Roldán et al. 2014). However, most analytical techniques proposed to determine AS are time-consuming, require very many man-hours and are rather tedious. Thus, these techniques are not adopted by most of the commercial soil laboratories and this discourages frequent soil physical health monitoring by farmers.

The aggregate size separation method proposed by Six et al. (1998) to study aggregate and soil organic $\mathrm{C}$ dynamics in response to soil management and use is being widely used (Mandiola et al.

CONTACT Gisela Vanesa García gisela.garcia@cyt.cic.gba.gob.ar E Área de Agronomía, Unidad Integrada Balcarce, Balcarce, Buenos Aires B7620BKL, Argentina

(C) 2020 Taylor \& Francis Group, LLC 
2011; Panettieri et al. 2017; Roldán et al. 2014; Sheehy et al. 2015; Six et al. 2004). As a consequence of this methodology, Six, Elliott, and Paustian (2000) proposed the calculation of the change of aggregate mean weight diameter $(\triangle \mathrm{MWD})$ as AS indicator. This methodology requires six sievings in water and, therefore, requires very many operator hours per sample and discourages its adoption by farmer-service soil laboratories. A simplification of the AS evaluation procedure would foster commercial soil laboratories to carry out AS evaluation as a service to producers and would encourage and facilitate frequent soil physical health monitoring.

Some intermediate results of the aggregate separation methodology and AS evaluation proposed by Six et al. $(1998,2000)$ would also indicate AS and could simplify AS evaluation. For example, a partial result of that methodology is the calculation of the aggregate mean weight diameter (MWD) after high aggression (i.e. sieving in water). This variable takes into account how many and with which distribution among sizes, aggregates are able to resist such aggression. Thus, MWD alone could be used as an AS indicator (Chaplot and Cooper 2015; King et al. 2019; Sarker et al. 2018; Scott, Baer, and Blair 2017) and could be obtained with a reduced number sievings. On the other hand, it has been reported that the stability of aggregates larger than $2000 \mu \mathrm{m}$ (large macroaggregates, MA) is very sensitive to management practices. Besides, it is generally considered that soil AS is defined by MA stability (Roldán et al. 2014; Scott, Baer, and Blair 2017). The remnant dry mass of MA after different levels of aggression are also intermediate steps of the methodology proposed by Six et al. (1998) and could be obtained with even less methodological steps.

We hypothesize that, for Mollisols with a wide range of soil texture classes within the loam texture-class group, a reduction in the number of operations to determine AS respect to that proposed by Six, Elliott, and Paustian (2000) would yield AS indicators as good as or better than $\triangle \mathrm{MWD}$. The aim of this work is to evaluate AS of a wide range of Mollisols from the southeastern Buenos Aires province (SBA) through $\triangle \mathrm{MWD}$, and other indicators that could be obtained as intermediate steps of the methodology of aggregate size separation proposed by Six et al. (1998).

\section{Materials and methods}

We used the results of the analyses of 196 soil samples taken from fields under agriculture (continuous cropping or crop-pasture rotations) and pseudo-pristine situations throughout the SBA. Part of those soil samples (137, Data A, Figure 1) had been taken between 2010 and 2016 both from private fields and plots of long-term experiments under long-lasting agriculture (85\% for more than $20 \mathrm{yr}, 11 \%$ between 11 and $20 \mathrm{yr}$, and $4 \%$ below $10 \mathrm{yr}$, approximately half of the samples), and from the corresponding situations free of or with low (no cropping) human intervention for long (i.e. at least $20 \mathrm{yr}$, situations assumed as similar to pristine condition (pseudo-pristine), the rest of Data A) (García et al. 2018; Mandiola et al. 2011; Roldán et al. 2014; Tourn et al. 2018). The other 59 samples (Data B) corresponded to a soil survey done in 2018 on private fields throughout the SBA under long-lasting cropping (at least $15 \mathrm{yr}$, approximately half of the samples) and the corresponding pseudo-pristine situations (the rest of Data B). Most situations under cropping were under notillage.

Composite soil samples (at least five sub-samples) were taken in the fall-winter with a shovel at $0-20 \mathrm{~cm}$ depth and with water content close to field capacity. The parts of the samples in contact with the shovel were discarded and only the core of each sub-sample was collected and carefully handled up to processing. All soils sampled are Mollisols and most of them are Udolls (Soil Survey Staff 2014). Soil textural classes were between sandy-loam, loam, clay-loam, and silty-clay-loam (Soil Survey Staff 2014). The ranges of mineral particle size content (determined by the hydrometer method, Gee and Bauder (1986)) were 264.7-695.7 $\mathrm{g}$ sand $\mathrm{kg}^{-1}$ mineral fraction, 101.1-379.3 $\mathrm{g}$ silt $\mathrm{kg}^{-1}$ mineral fraction, and $150.4-472.7 \mathrm{~g} \mathrm{clay} \mathrm{kg}^{-1}$ mineral fraction. Total and particulate organic carbon content at $0-20 \mathrm{~cm}$ (fractionated according to Cambardella and Elliott (1992) and carbon content determined by wet combustion maintaining reaction temperature for $90 \mathrm{~min}$, Schlichting, 


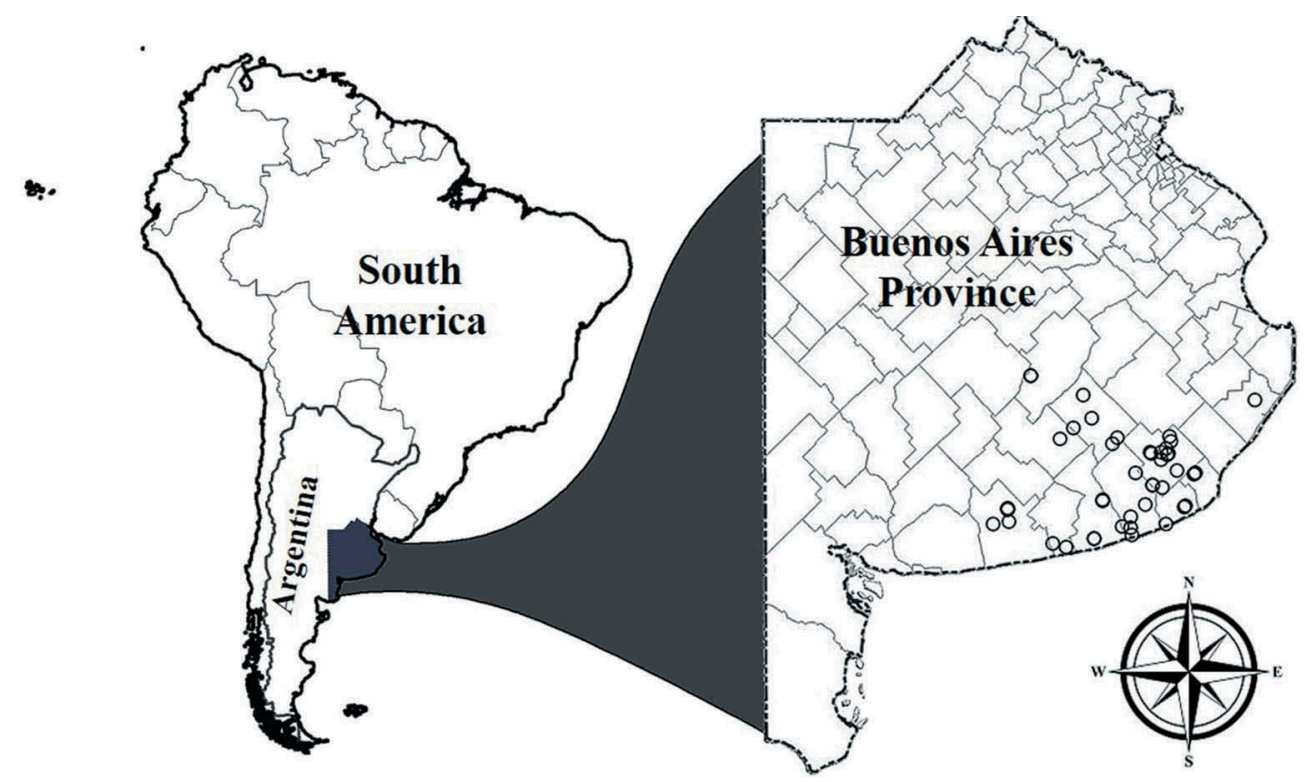

Figure 1. Sampling sites throughout the southeastern Buenos Aires province, Argentina.

Blume, and Stahr (1995)) ranged 16.5-61.1 $\mathrm{g} \mathrm{C} \mathrm{kg}^{-1}$ dry soil, and $0.98-28.5 \mathrm{~g} \mathrm{C} \mathrm{kg}^{-1}$ dry soil, respectively.

Immediately after extraction (i.e. in moist condition), the aggregates were carefully hand-split apart through their natural breakage lines up to passing an $8000-\mu \mathrm{m}$-mesh sieve. Afterward, the samples were oven-dried at $50^{\circ} \mathrm{C}$ until constant weight and then used to perform the methodology of aggregate separation after two different re-wetting pre-treatments (Six et al. 1998): i) capillary rewetting up to field capacity (CW), and ii) sudden immersion in water (violent re-wetting, VW). Afterward, re-wetted aggregates after each re-wetting procedure were subjected to successive sievings in water through sieves of decreasing mesh (Figure 2) to separate four aggregate size fractions. To capillary re-wet the aggregates, $100 \mathrm{~g}$ of each sample were placed on wet porous polypropylene sheets for $24 \mathrm{~h}$ at room temperature to allow slow re-wetting up to field capacity. On the other hand, another aliquot of $100 \mathrm{~g}$ of dry aggregates from each sample were suddenly submerged in water (VW) right before the first sieving. Before the first sieving, both capillary and violently re-wetted aggregates remained submerged in water for $5 \mathrm{~min}$ on the $2000-\mu \mathrm{m}$-mesh sieve. Later on, through successive sievings (50 3 -cm-run up and down oscillations during $2 \mathrm{~min}$ for each sieving) on different sieves (first 2000- $\mu \mathrm{m}$-mesh, second $250-\mu \mathrm{m}$-mesh, and third $53-\mu \mathrm{m}$-mesh) both aliquots of each sample were separated into four aggregate sizes: MA $(2000-8000 \mu \mathrm{m})$, small macroaggregates (Ma, 250-2000 $\mu \mathrm{m}$ ), microaggregates $(\mathrm{Mi}, 53-250 \mu \mathrm{m})$, and fine fraction (FF, <53 $\mu \mathrm{m}$ ) (Figure 2). The first three aggregate fractions were back-washed from the corresponding sieve, let flocculate for $24 \mathrm{~h}$, and, after removing the supernatant, oven-dried at $50^{\circ} \mathrm{C}$ up to constant weight. The FF dry mass was calculated as the difference between the initial aliquot mass $(100 \mathrm{~g})$ and the sum of the dry masses of the other three aggregate size fractions. Given more than $95 \%$ of the sand particle size fraction was below $250 \mu \mathrm{m}$ (fine and very fine sand, Soil Survey Staff 2014) (data not shown), according to Yamashita et al. (2006) we did not correct aggregate-size-fraction dry masses by sand content as originally indicated by Six, Elliott, and Paustian (2000).

With aggregate-size-fraction dry masses, we were able to calculate MWD (mm) resulting from sieving after $\mathrm{CW}\left(\mathrm{MWD}_{\mathrm{CW}}\right.$, Equation 1, Figure 2 (right side)) and after VW (MWD $\mathrm{VW}_{\mathrm{VW}}$, Equation 2, Figure 2 (left side)), and $\triangle \mathrm{MWD}(\mathrm{mm})$ as the difference between the $\mathrm{MWD}_{\mathrm{CW}}$ and $\mathrm{MWD}_{\mathrm{VW}}$ (Six, Elliott, and Paustian 2000) (Figure 2). 
VW

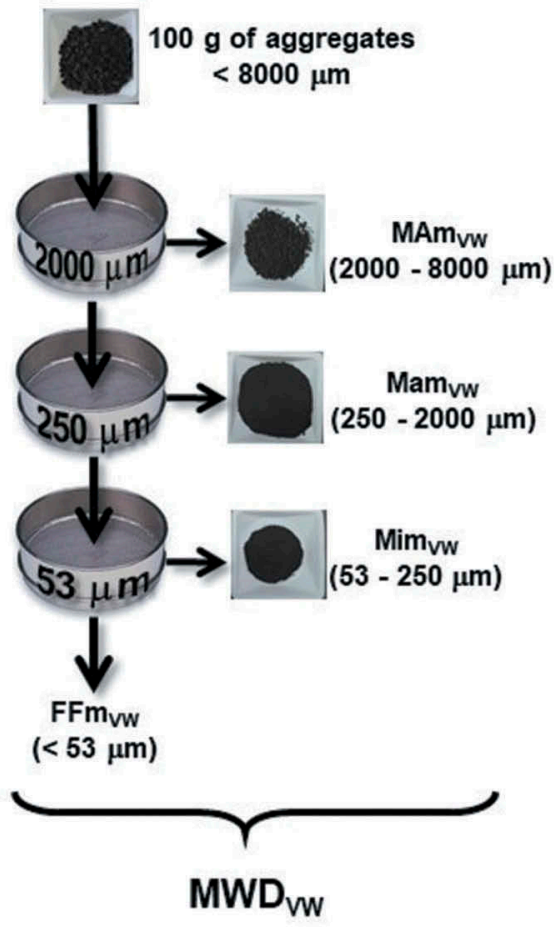

CW

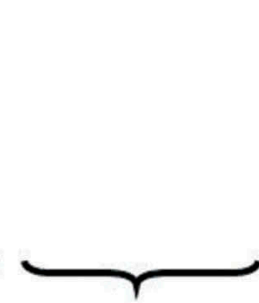

$\Delta \mathrm{MAm}_{\mathrm{vw}-\mathrm{cw}}$
$100 \mathrm{~g}$ of aggregates

$<8000 \mu \mathrm{m}$

$\sqrt{1}$

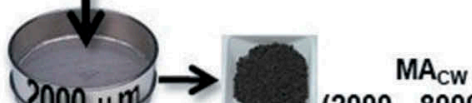

$(2000-8000 \mu \mathrm{m})$
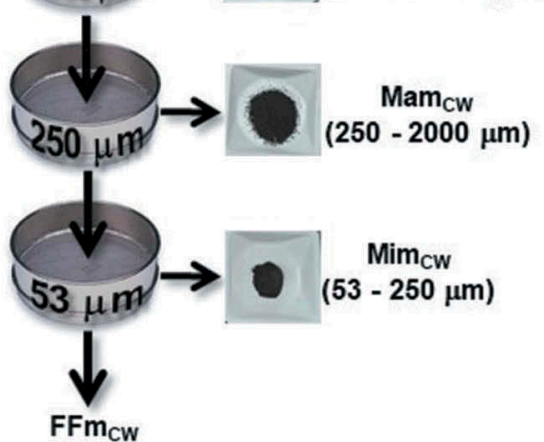

(<53 $\mu \mathrm{m}$ )

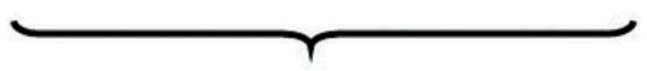

$\triangle M W D$

Figure 2. Scheme of the methodology for aggregate size separation. VW: sudden immersion re-wetting, CW: capillary re-wetting, MWD: mean weight diameter, $\triangle$ MWD: change of MWD between CW and VW, MAm: 2000-8000 $\mu$ m macroaggregate dry mass, Mam: 250-2000 $\mu \mathrm{m}$ macroaggregate dry mass, Mim: microaggregate dry mass, FFm: fine fraction dry mass.

$$
\begin{aligned}
& \mathrm{MWD}_{\mathrm{CW}}=\sum_{\mathrm{i}=1}^{4} \mathrm{X}_{\mathrm{i}} \mathrm{W}_{\mathrm{i}} \\
& \mathrm{MWD}_{\mathrm{VW}}=\sum_{\mathrm{i}=1}^{4} \mathrm{X}_{\mathrm{i}} \mathrm{W}_{\mathrm{i}}
\end{aligned}
$$

In Equations 1 and 2, i identifies each aggregate size fraction separated after $\mathrm{CW}$ (Equation 1) and VW (Equation 2) (i.e. MA (1), Ma (2), Mi (3), and FF (4)), respectively, $\mathrm{X}_{\mathrm{i}}$ is the mean diameter of the $\mathrm{i}$-th aggregate size fraction calculated as the arithmetic mean between the mesh opening of both sieves that define the $\mathrm{i}$-th aggregate size fraction, and $\mathrm{W}_{\mathrm{i}}$ is the proportion of the dry mass of the $\mathrm{i}$-th aggregate size fraction respect to the initial aliquot dry mass $(100 \mathrm{~g})$.

On the other hand, the aggregate size separation methodology proposed by Six et al. (1998) yields other variables that could be used as AS indicators: i) remnant MA dry mass resulting from sieving both after VW $\left(\mathrm{MAm}_{\mathrm{VW}}, \mathrm{g}\right.$ MA $(100 \mathrm{~g})^{-1}$ dry soil, Figure 2 (first step of left side)) and after $\mathrm{CW}\left(\mathrm{MAm}_{\mathrm{CW}}, \mathrm{g} \mathrm{MA}(100 \mathrm{~g})^{-1}\right.$ dry soil, Figure 2 (first step of right side)), and ii) the difference between $\mathrm{MAm}_{\mathrm{VW}}$ and $\mathrm{MAm}_{\mathrm{CW}}$ (change of MA mass, $\Delta \mathrm{MAm} \mathrm{m}_{\mathrm{VW}-\mathrm{CW}}, \mathrm{g} \mathrm{MA}(100 \mathrm{~g})^{-1}$ dry soil, Figure 2). 
Statistical analyses were done with $\mathrm{R}$ ( $\mathrm{R}$ Core Team 2018). Data A was used to evaluate the relationships among variables through Pearson correlation coefficients and the fitting of linear simple regression models. Data B was used to validate the models fitted to Data A. The significance level used was 0.05 .

\section{Results}

Table 1 shows the maximum and minimum values, and the mean and median of all AS indicators analyzed in this work (i.e. $\triangle \mathrm{MWD}, \mathrm{MWD}_{\mathrm{CW}}, \mathrm{MWD}_{\mathrm{VW}}, \Delta \mathrm{MAm}_{\mathrm{VW}-\mathrm{CW}}, \mathrm{MAm}_{\mathrm{VW}}$, and $\mathrm{MAm}_{\mathrm{CW}}$ ). As shown in Table 1, the number of sievings needed to obtain the AS indicators decreases as follows $\triangle \mathrm{MWD}$ $>\mathrm{MWD}_{\mathrm{CW}}=\mathrm{MWD}_{\mathrm{VW}}>\Delta \mathrm{MAm}_{\mathrm{VW}-\mathrm{CW}}>\mathrm{MAm}_{\mathrm{VW}}=\mathrm{MAm}_{\mathrm{CW}}$. On the other hand, to obtain $\Delta \mathrm{MWD}$, $\mathrm{MWD}_{\mathrm{CW}}, \Delta \mathrm{MAm}_{\mathrm{VW}-\mathrm{CW}}, \mathrm{MAm}_{\mathrm{CW}}$ it is needed an overnight incubation to capillary re-wet dry aggregates.

Table 2 shows Pearson correlation coefficients among all six variables taken by two. The highest correlation coefficients were between both AS indicators that involve the evaluation of changes between re-wetting procedures (i.e. $\triangle \mathrm{MWD}$ and $\triangle \mathrm{MAm} \mathrm{mW}_{\mathrm{V}-\mathrm{CW}}$ ) and between those indicators that involve both re-wetting procedures separately (i.e. $\mathrm{MWD}_{\mathrm{CW}}$ and $\mathrm{MAm}_{\mathrm{CW}}$, on one side, and $\mathrm{MWD}_{\mathrm{VW}}$ and $\mathrm{MAm}_{\mathrm{VW}}$, on the other). However, correlation coefficients of those AS indicators after $\mathrm{CW}$ (i.e. $\mathrm{MWD}_{\mathrm{CW}}$ or $\mathrm{MAm}_{\mathrm{CW}}$ ) with the rest of the indicators were much lower, although between $\mathrm{MWD}_{\mathrm{CW}}$ and $\mathrm{MAm}_{\mathrm{CW}}$ the coefficient was 1 .

\section{Discussion}

Evaluation of AS focuses on how aggregates resist external aggressions and, if the method subjects the aggregates to different levels of aggression, the rate of change between them could be evaluated (Kemper and Rosenau 1986). With the re-wetting procedures of the method proposed by Six et al. (1998) aggregates undergo two levels of aggression. Under CW water enters aggregate porosity slowly and the air is allowed going out without generating internal pressures (Cambardella and Elliott 1993). Thus, aggregates are less disturbed by sieving in water after CW because they are less exposed to internal forces and their stability is maximum when the water content is close to field capacity (Hofman and de Leenheer 1975). On the other hand, when dry aggregates are suddenly submerged (i.e. VW), water enters the pores abruptly and traps and compresses air within them.

Table 1. Maximum and minimum values, mean and median of indicators of aggregate stability at $0-20 \mathrm{~cm}$ depth: change of mean weight diameter (MWD) between capillary re-wetting (CW) and re-wetting by sudden immersion (VW) $(\triangle M W D, m m), M W D$ after $C W\left(M W D_{C W}, m m\right), M W$ after $V W\left(M W D_{W_{1}}\right)$, change of 2000-8000 $\mu m$ macroaggregate (MA) dry mass between VW and CW $\left(\triangle M A m_{\mathrm{VW}-\mathrm{CW}}, \mathrm{g}(100 \mathrm{~g})^{-1}\right)$, MA dry mass remnant after VW $\left(\mathrm{MAm}_{\mathrm{VW}}, \mathrm{g}(100 \mathrm{~g})^{-1}\right)$, and MA dry mass remnant after $\mathrm{CW}\left(\mathrm{MAm}_{\mathrm{CW}}, \mathrm{g}(100 \mathrm{~g})^{-1}\right)$. \# of sievings: number of sievings needed to obtain the variable, Data A: soil sampling between 2010 and 2016, Data B: soil sampling in 2018.

\begin{tabular}{|c|c|c|c|c|c|}
\hline Variable & \# of sievings & Minimum & Maximum & Mean & Median \\
\hline \multicolumn{6}{|c|}{ Data $A(n=137)$} \\
\hline$\triangle \mathrm{MWD}$ & 6 & 0 & 3.17 & 1.67 & 1.74 \\
\hline $\mathrm{MWD}_{\mathrm{CW}}$ & 3 & 1.82 & 4.52 & 3.46 & 3.58 \\
\hline$M W D_{\mathrm{VW}}$ & 3 & 0.35 & 3.96 & 1.79 & 1.53 \\
\hline$\Delta M A m_{\mathrm{VW}-\mathrm{CW}}$ & 2 & -74.2 & 2.36 & -38.4 & -38.0 \\
\hline$M m_{V w}$ & 1 & 0.72 & 74.9 & 25.5 & 18.9 \\
\hline MAm $_{\mathrm{CW}}$ & 1 & 27.2 & 89.2 & 63.9 & 66.5 \\
\hline \multicolumn{6}{|c|}{ Data B $(n=59)$} \\
\hline$\triangle M W D$ & 6 & 0.06 & 2.94 & 1.71 & 1.87 \\
\hline $\mathrm{MWD}_{\mathrm{CW}}$ & 3 & 2.80 & 4.30 & 3.46 & 3.43 \\
\hline$M W D_{V W}$ & 3 & 0.70 & 3.48 & 1.75 & 1.64 \\
\hline$\Delta \mathrm{MAm}_{\mathrm{VW}-\mathrm{CW}}$ & 2 & -69.5 & 1.11 & -40.4 & -44.5 \\
\hline$M_{\text {MW }}$ & 1 & 3.29 & 64.2 & 23.8 & 20.4 \\
\hline $\mathrm{MAm}_{\mathrm{CW}}$ & 1 & 49.4 & 83.1 & 64.2 & 63.3 \\
\hline
\end{tabular}


Table 2. Pearson correlation coefficients of the relationships between aggregate stability indicators from Data A (soil sampling between 2010 and 2016) taken by two: change of mean weight diameter (MWD) between capillary re-wetting (CW) and re-wetting by sudden immersion (VW) $(\triangle M W D, m m), M W D$ after $C W\left(M W D_{C W}, m m\right), M W$ after VW $\left(M W D_{V w}, m m\right)$, change of $2000-8000 \mu m$

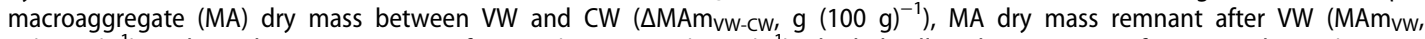
$\left.\mathrm{g}(100 \mathrm{~g})^{-1}\right)$, and MA dry mass remnant after CW (MAm $\left.\mathrm{CW}_{\mathrm{W}} \mathrm{g}(100 \mathrm{~g})^{-1}\right)$. Shaded cells indicate not significant correlation $(p>.05$, $\mathrm{n}=137)$ all the rest of correlations were highly significant $(p<.01, \mathrm{n}=137)$.

\begin{tabular}{lcccrrr}
\hline & $\Delta$ MWD & MWD $_{\mathrm{CW}}$ & $\mathrm{MWD}_{\mathrm{VW}}$ & $\Delta \mathrm{MAm}_{\mathrm{VW}-\mathrm{CW}}$ & $\mathrm{MAm}_{\mathrm{VW}}$ & $\mathrm{MAm}_{\mathrm{CW}}$ \\
\hline$\Delta$ MWD & 1.00 & 0.13 & -0.79 & -0.99 & -0.84 & 0.14 \\
MWD $_{\mathrm{CW}}$ & & 1.00 & 0.50 & -0.23 & 0.42 & 1.00 \\
MWD $_{\mathrm{VW}}$ & & & 1.00 & 0.73 & 0.99 & 0.49 \\
$\Delta$ MAm $_{\mathrm{VW}-\mathrm{CW}}$ & & & & 1.00 & 0.79 & -0.24 \\
MAm $_{\mathrm{VW}}$ & & & & & 1.00 & 0.41 \\
MAm $_{\mathrm{CW}}$ & & & & & & 1.00 \\
\hline
\end{tabular}

This generates internal pressure that may produce aggregate slaking and/or make aggregates more susceptible to slaking upon sieving (Cambardella and Elliott 1993). Thus, resulting aggregate mass after CW includes very stable aggregates and also aggregates with different levels of stability that were able to resist the level of aggression imposed. On the other hand, resulting aggregate mass after VW includes only the very stable aggregates that resisted high aggression (Roldán et al. 2014). As a consequence, average or median remnant mass of MA was greater after CW than after VW $\left(\mathrm{MAm}_{\mathrm{CW}}>\mathrm{MAm}_{\mathrm{VW}}\right.$, Table 1$)$, and aggregate size distribution after $\mathrm{VW}$ appeared displaced toward smaller aggregates respect to $\mathrm{CW}$ (average or median $\mathrm{MWD}_{\mathrm{VW}}<\mathrm{MWD}_{\mathrm{CW}}$, Table 1). However, correlation coefficients between AS indicators after $\mathrm{CW}$ (i.e. $\mathrm{MWD}_{\mathrm{CW}}$ or $\mathrm{MAm}_{\mathrm{CW}}$ ) and the rest of the indicators were lower or non-significant (Table 2). This could be attributed to the different composition of the remnant mass after sieving after both re-wetting procedures and what they represent. While variables after VW is shown only how many aggregates are stable, variables after CW show a mixture of aggregates of different stability with a proportion somehow uncertain. Therefore, the usefulness of $\mathrm{MAm}_{\mathrm{CW}}$ and $\mathrm{MWD}_{\mathrm{CW}}$ as AS indicators by themselves would be erratic.

The weaker the aggregation forces the more susceptible the aggregates to breaking off when sieved in water both after CW and after VW. However, it would be expected that the difference in aggregate breakage between aggression levels was greater as the stability of soil structure was lower. Change of MWD has been widely and successfully used in the SBA to evaluate AS as a function of mostly loam soil use of soils mostly loam and with high organic matter content (Mandiola et al. 2011; Roldán et al. 2014; Tourn et al. 2018). Nonetheless, Tourn et al. (2019) showed that $\Delta$ MWD determined with the same method (Six, Elliott, and Paustian 2000; Six et al. 1998) was not able to distinguish AS of soils under contrasting management as clearly as other methods.

Table 2 shows that $\triangle \mathrm{MAm} \mathrm{VW}_{\mathrm{VW}-\mathrm{CW}}$ highly correlated with $\triangle \mathrm{MWD}$. This allows inferring that the $\triangle \mathrm{MWD}$ is determined almost exclusively by $\triangle \mathrm{MAm}_{\mathrm{VW}-\mathrm{CW}}$. Hence, to evaluate AS it would not be necessary to separate aggregates $<2000 \mu \mathrm{m}$ (i.e. 250-2000, 53-250 y $<53 \mu \mathrm{m}$ ) to determine $\mathrm{MWD}_{\mathrm{CW}}$ and $\mathrm{MWD}_{\mathrm{VW}}$ to calculate $\triangle \mathrm{MWD}$. According to this, AS evaluation could be achieved reducing the number of sievings from six to determine $\triangle \mathrm{MWD}$ (Table 1, Six et al. 1998, Six, Elliott, and Paustian 2000) to only two sievings to determine $\Delta \mathrm{MAm}_{\mathrm{VW}-\mathrm{CW}}$ (Table 1). However, for soils with very low aggregate stability, neither $\triangle \mathrm{MWD}$ nor $\triangle \mathrm{MAm} \mathrm{m}_{\mathrm{VW}-\mathrm{CW}}$ showed as good AS indicators. Figure 3 shows an example comparing both variables (Figure $3 \mathrm{a}$ for $\triangle \mathrm{MWD}$ and Figure $3 \mathrm{~b}$ $\triangle \mathrm{MAm}_{\mathrm{VW}-\mathrm{CW}}$ ) for a sandy loam soil (supposedly low AS) and a clay loam soil (supposedly high AS). In both situations, both $\triangle \mathrm{MWD}$ and $\triangle \mathrm{MAm} \mathrm{VWW}_{\mathrm{VW}}$ were low and similar between soils which could be interpreted as high AS for both soils. Nevertheless, MAm ${ }_{C W}, M_{V w}$ (Figure 3a), $\mathrm{MWD}_{\mathrm{CW}}$, and $\mathrm{MAm}_{\mathrm{CW}}$ (Figure $3 \mathrm{~b}$ ) of the sandy soil were much lower than those of the clay loam soil, indicating that the former soil is more unstable than the latter one. Therefore, $\triangle \mathrm{MWD}$ and $\triangle \mathrm{MAm}_{\mathrm{VW}-\mathrm{CW}}$ failed to allow distinguishing two soils with different stability due to their inherent characteristics (Figure 3). 

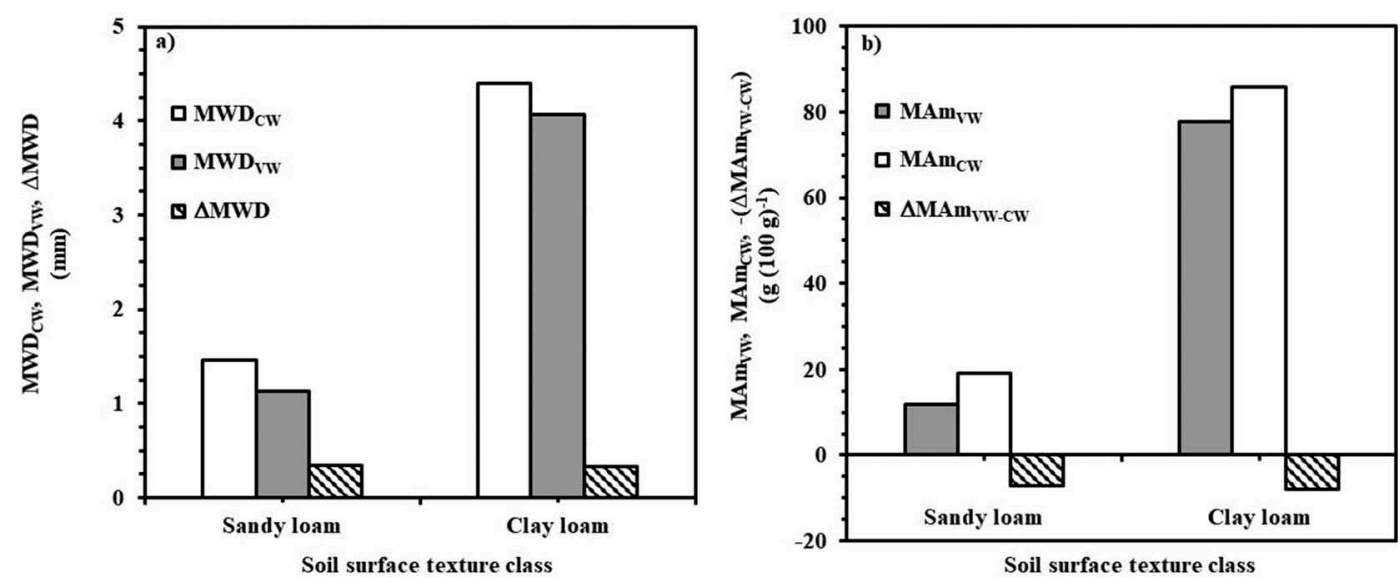

Figure 3. a) Mean weight diameter (MWD) after capillary re-wetting $\left(C W, M W D_{C W}\right)$ and after sudden immersion re-wetting (VW, $\left.M W D_{V W}\right)$, and change of MWD between CW and VW ( $\left.\triangle M W D\right)$; b) remnant dry mass remnant of 2000-8000 $\mu$ m macroaggregates $(\mathrm{MAm})$ after VW $\left(\mathrm{MAm}_{\mathrm{VW}}\right)$ and after $\mathrm{CW}\left(\mathrm{MAm}_{\mathrm{CW}}\right)$ and change of MAm between VW and CW ( $\triangle M A m_{\mathrm{VW}}$-CW) in two soils with different textures and organic carbon content: sandy loam $\left(684.2 \mathrm{~g} \mathrm{~kg}^{-1}\right.$ of sand, $103.6 \mathrm{~g} \mathrm{~kg}^{-1}$ of clay, 26.9 of total organic carbon $\mathrm{g} \mathrm{kg}^{-1}$, and $7.24 \mathrm{~g} \mathrm{~kg}^{-1}$ of particulate organic carbon) and clay loam $\left(271.4 \mathrm{~g} \mathrm{~kg}^{-1}\right.$ of sand, $333.1 \mathrm{~g} \mathrm{~kg}^{-1}$ of clay, $92.9 \mathrm{~g} \mathrm{~kg}$ - of total organic carbon, and $48.7 \mathrm{~g} \mathrm{~kg}^{-1}$ of particulate organic carbon).

Given the remnant soil mass after sieving after VW includes only stable aggregates that resisted very high aggression, this part of the aggregate separation procedure (Figure 2, left side) would yield valuable AS indicators. As a matter of fact, $\mathrm{MWD}_{\mathrm{Vw}}$ is widely used as an AS indicator (Chaplot and Cooper 2015; King et al. 2019; Sarker et al. 2018; Scott, Baer, and Blair 2017). The lower MWD $\mathrm{VW}_{\mathrm{V}}$ the lower AS given the proportion of remnant larger aggregates diminishes and this leads to a reduction of MWD. Moreover, the determination of $\mathrm{MWD}_{\mathrm{VW}}$ requires only three sievings in comparison with the determination of $\triangle \mathrm{MWD}$ (Figure 2) and no incubation before sievings. On the other hand, $\mathrm{MWD}_{\mathrm{VW}}$ correlated very closely with $\mathrm{MAm}_{\mathrm{MV}}$ (Table 2) which indicates that $\mathrm{MWD}_{\mathrm{VW}}$ is determined almost exclusively by $\mathrm{MAm}_{\mathrm{VW}}$ and that there is no need to determine the remnant mass of the rest of the aggregate size fractions (i.e. 250-2000, 53-250 y $<53 \mu \mathrm{m}$ ). With Data A a simple linear regression model was fitted of $\mathrm{MWD}_{\mathrm{VW}}$ on $\mathrm{MAm}_{\mathrm{MV}}$ (Figure 4). With Data B the regression model (Figure 4) was validated through fitting another simple regression model (Figure 5) of observed $\mathrm{MWD}_{\mathrm{VW}}$ (Data $\mathrm{B}$ ) on simulated $\mathrm{MWD}_{\mathrm{VW}}$ (with the observed $\mathrm{MAm}_{\mathrm{MV}}$ (Data B) and the model of Figure 4). The slope and the intercept of the model in Figure 5 were not statistically different from one and zero, respectively. These results indicate that AS could be evaluated through remnant dry mass of aggregates between 2000 and $8000 \mu \mathrm{m}$ diameter after only one sieving for $2 \mathrm{~min}$ after sudden immersion of dry aggregates in water for $5 \mathrm{~min}$. This greatly simplifies the methodology proposed by Six et al. (1998), (2000)) and would allow frequent AS monitoring in fields under agriculture.

\section{Conclusion}

The results of this work support the hypothesis. The determination of AS of loamy Mollisols could be simplified by reducing the number of sievings in water. This is so since $\mathrm{MAm}_{\mathrm{VW}}$, that requires only one sieving in water on a $2000-\mu \mathrm{m}$ mesh sieve without a previous incubation period, is a good indicator of AS. Hence, frequent soil physical health monitoring through AS determination using $\mathrm{MAm}_{\mathrm{MV}}$, is facilitated. 


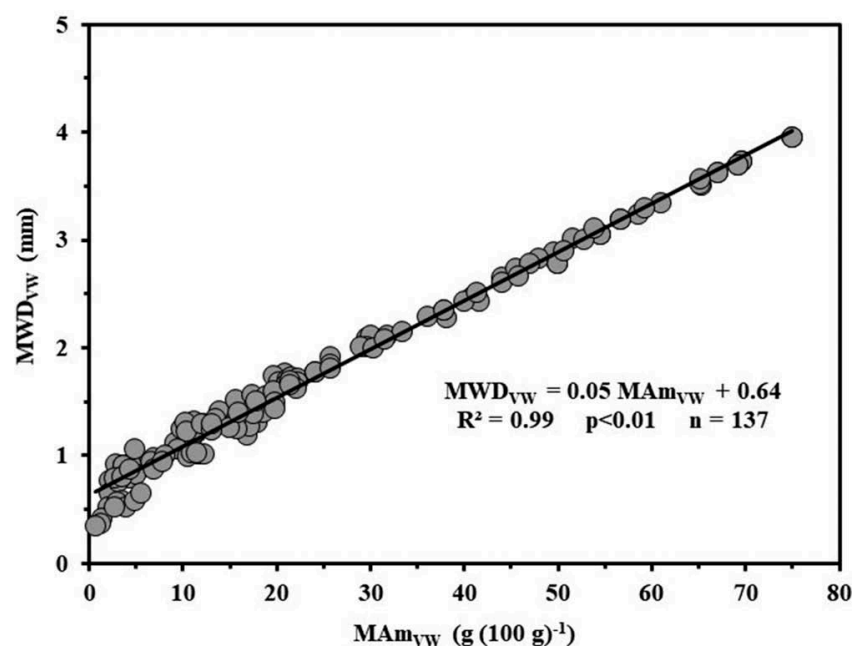

Figure 4. Simple linear regression model between mean weight diameter after sudden immersion re-wetting (MWD $(M w)$ and 2000-8000 $\mu \mathrm{m}$ macroaggregate dry mass remnant after sudden immersion re-wetting (MAm $\left.\mathrm{vw}_{\mathrm{w}}\right)$.

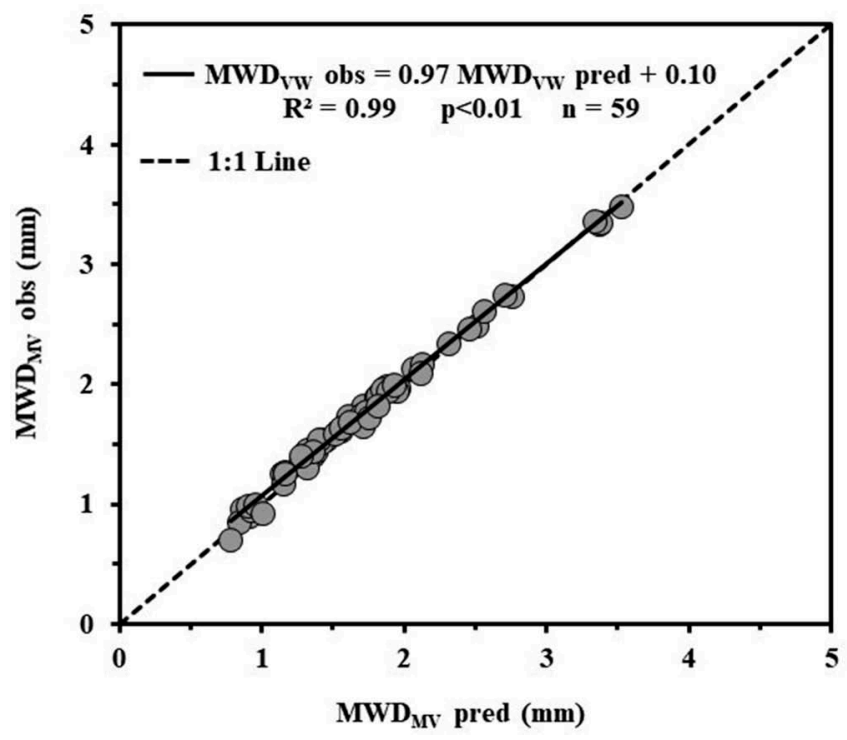

Figure 5. Simple linear regression model between observed mean weight diameter after sudden immersion re-wetting (MWD $\left.\mathrm{Vw}_{\mathrm{V}}\right)$ and the predicted $M W D_{\mathrm{Vw}}$ with the model shown in Figure 4.

\section{Acknowledgments}

The information presented in this work is part of the Doctoral Theses of the first two authors, the Master of Science Thesis of the third author (Programa de Posgrado en Ciencias Agrarias [Graduate Program in Agricultural Sciences], Facultad de Ciencias Agrarias [Agricultural Sciences Faculty], Universidad Nacional de Mar del Plata [National University of Mar del Plata]), and the Graduation Thesis of the fourth author at the Facultad de Ciencias Agrarias [Agricultural Sciences Faculty], Universidad Nacional de Mar del Plata [National University of Mar del Plata]. 


\section{Funding}

This work was supported by the Universidad Nacional de Mar del Plata [National University of Mar del Plata] under Grants [AGR570/18 and AGR595/19], and the Instituto Nacional de Tecnología Agropecuaria [National Institute of Agricultural Techonlogy] under Grant [PNCyO 1127032].

\section{ORCID}

Gisela Vanesa García (D) http://orcid.org/0000-0002-0628-7917

Guillermo Alberto Studdert (iD http://orcid.org/0000-0002-8611-4441

\section{References}

Aparicio, V. C., and J. L. Costa. 2007. Soil quality indicators under continuous cropping systems in the Argentinean pampas. Soil and Tillage Research 96:155-65. doi:10.1016/j.still.2007.05.006.

Bronick, C. J., and R. Lal. 2005. Soil structure and management: A review. Geoderma 124:3-22. doi:10.1016/j. geoderma.2004.03.005.

Cambardella, C., and E. Elliott. 1992. Particulate soil organic matter. Changes across a grassland cultivation sequence. Soil Science Society of America Journal 56:777-83. doi:10.2136/sssaj1992.03615995005600030017x.

Cambardella, C., and E. Elliott. 1993. Carbon and nitrogen distribution in aggregates from cultivated and native grassland soils. Soil Science Society of America Journal 57:1071-76. doi:10.2136/ sssaj1993.03615995005700040032x.

Chaplot, V., and M. Cooper. 2015. Soil aggregate stability to predict organic carbon outputs from soils. Geoderma 243-244:205-13. doi:10.1016/j.geoderma.2014.12.013.

García, G. V., G. A. Studdert, S. San Martino, N. Wyngaard, N. I. Reussi Calvo, and F. Covacevich. 2018. Nitrógeno mineralizado en anaerobiosis como indicador de la estabilidad de agregados [Mineralized nitrogen under anaerobiosis as indicator of aggregate stability]. In Proceedings of the XXVI Congreso Argentino de la Ciencia del Suelo [XXVI Argentinean Soil Science Congress], CD-ROM. San Miguel de Tucumán, Tucumán, Argentina: Argentinean Soil Science Association.

Gee, W., and J. Bauder. 1986. Particle-size analysis. In Methods of soil analysis. Part 1. Physical and mineralogical methods. ed. A. Klute, 2nd ed., 383-410. Madison, WI: ASA and SSSA. doi:10.2136/sssabookser5.1.2ed.c15.

Hofman, G., and L. de Leenheer. 1975. Influence of soil prewetting on aggregate stability. Pedologie 25:190-98.

Kemper, W., and R. Rosenau. 1986. Aggregate stability and size distribution. In Methods of soil analysis. Part 1. Physical and mineralogical methods. ed. A. Klute, 2nd ed., 425-42. Madison, WI: ASA and SSSA. doi:10.2136/ sssabookser5.1.2ed.c17.

King, A. E., K. A. Congreves, B. Deen, K. E. Dunfield, R. P. Voroney, and C. Wagner-Riddle. 2019. Quantifying the relationships between soil fraction mass, fraction carbon, and total soil carbon to assess mechanisms of physical protection. Soil Biology and Biochemistry 135:95-107. doi:10.1016/j.soilbio.2019.04.019.

Mandiola, M., G. A. Studdert, G. F. Domínguez, and C. C. Videla. 2011. Organic matter distribution in aggregate sizes of a Mollisol under contrasting managements. Journal of Soil Science and Plant Nutrition 11:41-57. doi:10.4067/ S0718-95162011000400004.

Panettieri, M., C. Rumpel, M. Dignac, and A. Chabbi. 2017. Does grassland introduction into cropping cycles affect carbon dynamics through changes of allocation of soil organic matter within aggregate fractions? Science of the Total Environment 576:251-63. doi:10.1016/j.scitotenv.2016.10.073.

R Core Team. 2018. R: A language and environment for statistical computing. R Foundation for Statistical Computing, Vienna, Austria. Accessed November 16, 2018. https:/www.R-project.org/.

Rabot, E., M. Wiesmeier, S. Schlüter, and H. J. Vogel. 2018. Soil structure as an indicator of soil functions: A review. Geoderma 314:122-37. doi:10.1016/j.geoderma.2017.11.009.

Roldán, M. F., G. Studdert, C. C. Videla, S. San Martino, and L. I. Picone. 2014. Distribución de tamaño y estabilidad de agregados en molisoles bajo labranzas contrastantes [Aggregate size distribution and stability in mollisols under contrasting tillage systems]. Ciencia del Suelo 32:247-57.

Sarker, J. R., B. P. Singh, A. L. Cowie, Y. Fang, D. Collins, W. Badgery, and R. C. Dalal. 2018. Agricultural management practices impacted carbon and nutrient concentrations in soil aggregates, with minimal influence on aggregate stability and total carbon and nutrient stocks in contrasting soils. Soil and Tillage Research 178:209-23. doi:10.1016/ j.still.2017.12.019.

Schlichting, E., H. P. Blume, and K. Stahr. 1995. Bodenkundliches Praktikum. Hamburg, Germany: Paul Parey.

Scott, D. A., S. G. Baer, and J. M. Blair. 2017. Recovery and relative influence of root, microbial, and structural properties of soil on physically sequestered carbon stocks in restored grassland. Soil Science Society of America Journal 81:50-60. doi:10.2136/sssaj2016.05.0158. 
Sheehy, J., K. Regina, L. Alakukku, and J. Six. 2015. Impact of no-till and reduced tillage on aggregation and aggregate-associated carbon in Northern European agroecosystems. Soil and Tillage Research 150:107-13. doi:10.1016/j.still.2015.01.015.

Six, J., H. Bossuyt, S. Degryze, and K. Denef. 2004. A history of research on the link between (micro) aggregates, soil biota, and soil organic matter dynamics. Soil and Tillage Research 79:7-31. doi:10.1016/j.still.2004.03.008.

Six, J., E. T. Elliott, and K. Paustian. 2000. Soil structure and soil organic matter: II. A normalized stability index and the effect of mineralogy. Soil Science Society of America Journal 64:1042-49. doi:10.2136/sssaj2000.6431042x.

Six, J., E. T. Elliott, K. Paustian, and J. W. Doran. 1998. Aggregation and soil organic matter accumulation in cultivated and native grassland soils. Soil Science Society of America Journal 62:1367-77. doi:10.2136/ sssaj1998.03615995006200050032x.

Soil Survey Staff. 2014. Keys to soil taxonomy. Washington, DC: USDA, Natural Resources Conservation Service.

Tourn, S. N., M. A. Agostini, G. F. Domínguez, and G. A. Studdert. 2019. Comparación de métodos para la determinación de estabilidad de agregados en molisoles del sudeste bonaerense [Comparison of methods to determine aggregate stability of mollisols from the southeastern Buenos Aires province]. In Proceedings of the XXII Congreso Latinoamericano de la Ciencia del Suelo [XXII Latinamerican Soil Science Congress], CD-ROM. Montevideo, Uruguay: Latinamerican Soil Science Society.

Tourn, S. N., G. A. Studdert, C. C. Videla, and G. Domínguez. 2018. Intensificación de sistemas de cultivo mediante rotación con pasturas y siembra directa para mejorar la macroagregación [Cropping system intensification through rotation with pastures and no-tillage to improve macroaggregation]. In Proceedings of the XXVI Congreso Argentino de la Ciencia del Suelo [XXVI Argentinean Soil Science Congress], CD-ROM. San Miguel de Tucumán, Tucumán, Argentina: Argentinean Soil Science Association.

Yamashita, T., H. Flessa, B. John, M. Helfrich, and B. Ludwig. 2006. Organic matter in density fractions of water-stable aggregates in silty soils: Effect of land use. Soil Biology and Biochemistry 38:3222-34. doi:10.1016/j. soilbio.2006.04.013. 